\title{
A INSERÇÃO DA EDUCAÇÃO AMBIENTAL NA EDUCAÇÃO BÁSICA: QUE FONTES DE INFORMAÇÃO OS PROFESSORES UTILIZAM PARA SUA FORMAÇÃO?
}

\author{
The insertion of the environmental education \\ in Basic School: which information sources \\ do the teachers use in their own training?
}

\author{
Marília Freitas de Campos Tozoni-Reis ${ }^{1}$ - Jandira Liria Biscalquini \\ Talamoni ${ }^{2}$. Sonia Silveira Ruiz ${ }^{3}$. Juliana Pereira Neves ${ }^{4}$. \\ Lucas André Teixeira ${ }^{5}$. Luciana Falcon Cassini ${ }^{6}$. Marina Battistetti \\ Festozo $^{7}$. Nadja Janke ${ }^{8}$. Jorge Sobral da Silva Maia ${ }^{9}$. Helena Maria \\ da Silva Santos ${ }^{10}$. Lilian Giacomini Cruz ${ }^{11}$. Regina Helena Munhoz ${ }^{12}$
}

\begin{abstract}
Resumo: Reconhecendo que as publicações acadêmicas sobre educação e educação ambiental raramente chegam às escolas, o Grupo de Pesquisa em educação ambiental da Universidade Estadual Paulista (UNESP), campus de Bauru, desenvolveu um estudo coletivo a fim de identificar quais fontes de informação os(as) professores(as) da Educação Básica utilizam em seu processo de formação sobre educação ambiental. Nosso objetivo geral foi, de posse dessas informações, estabelecer diretrizes para que as publicações de nossas pesquisas cheguem - e de maneira mais significativa - às escolas, contribuindo, assim, para a inserção da educação ambiental nesse espaço. Trata-se de um estudo qualitativo na modalidade pesquisa de campo, cujos dados para análise foram coletados por observações nas escolas e entrevistas com cerca de trezentos professores em 14 municípios da região central do Estado de São Paulo. Apresentamos, neste artigo, nossas conclusões acerca, especificamente, das fontes de informação utilizadas pelos professores entrevistados.
\end{abstract}

Palavras-chave: Educação ambiental. Fontes de informação. Educação Básica. Políticas públicas.

\begin{abstract}
Recognizing that academic publications on education and environmental education rarely reach school, our Research Group on Environmental Education (UNESP-Bauru) developed a collective study seeking to identify which sources of information basic education teachers use in their training process on environmental education. Our general aim was, having this information, to establish guidelines for our research publications to reach the schools, contributing, thus, to the inclusion of environmental education in this space. This study was based on qualitative approach, employing field research, and the data for analysis were collected through observations in schools and interviews with about three hundred teachers in 14 cities in São Paulo State central region. We present here our conclusions, specifically, the sources of information used by the teachers.
\end{abstract}

Keywords: Environmental education. Sources of information. Basic education. Public policies. 


\section{Introdução}

O Censo Escolar de 2001, o primeiro a incluir uma questão sobre educação ambiental (EA), constatou que $61,2 \%$ de todas as escolas brasileiras declararam trabalhar com esta temática, e, mais tarde, no ano de 2004, este percentual saltou para 94\% (VEIGA; AMORIM; BLANCO, 2006). Os resultados desses dois censos mostram que, atualmente, a EA está presente em muitas escolas. Além disso, o estudo intitulado 'O que fazem as escolas que dizem que fazem educação ambiental?’ (TRAJBER; MENDONÇA, 2006), realizado pelo Instituto Nacional de Estudos e Pesquisas Educacionais Anísio Teixeira (INEP), do Ministério da Educação (MEC), em escolas de Ensino Fundamental e Médio de todo o país, também identificou dados importantes sobre isso. Na região sudeste, o Relatório da Pesquisa mostra que um percentual significativo das escolas que praticam EA iniciou seus trabalhos baseados na iniciativa de um professor ${ }^{13}$ ou grupo de professores, em um problema ambiental do bairro ou por iniciativa dos alunos. Ainda neste contexto, os fatores mais importantes da inserção dessa prática nas escolas foram: a presença de professores qualificados com formação superior e especializados, professores 'idealistas' que atuam como lideranças e, em seguida, a formação continuada de professores. Se a inserção da EA na escola está a cargo dos professores, perguntamos: como estes se preparam para tal?

A pesquisa do INEP identificou que uma das grandes dificuldades para a inserção da EA nas escolas refere-se à precariedade de recursos materiais, em que estão inseridos os materiais de pesquisa e estudo para o aprofundamento de temas ambientais e educacionais, inclusive para a formação permanente dos professores. Sem material adequado e em quantidade suficiente para realizar seus trabalhos, eles procuram fontes diversas, nem sempre com adequada qualidade acadêmica e científica, o que vem prejudicando o trabalho desenvolvido. Sendo assim, pareceu-nos relevante identificar que materiais os professores utilizam para a

\footnotetext{
${ }^{1}$ Instituto de Biociências, UNESP - Univ Estadual Paulista, campus de Botucatu, Departamento de Educação. Programa de Pós-graduação em Educação para a Ciência, UNESP - Univ Estadual Paulista, campus de Bauru, Departamento de Educação. Caixa postal 246, Botucatu, SP, Brasil. Email: <mariliaedu@ibb.unesp.br>. ${ }^{2}$ Faculdade de Ciências, UNESP - Univ Estadual Paulista, campus de Bauru, Departamento de Biologia e Programa de Pós-graduação em Educação para a Ciência, Bauru, SP, Brasil.

${ }^{3}$ Instituto de Ciências da Saúde, Universidade Paulista (UNIP), Bauru, SP, Brasil.

4,7,8,11 Faculdade de Ciências, UNESP - Univ Estadual Paulista, campus de Bauru, Programa de Pós-Graduação em Educação para a Ciência, Bauru, SP, Brasil.

${ }^{5}$ Núcleo de Pesquisas em Novas Arquiteturas Pedagógicas, Universidade de São Paulo (USP), São Paulo, SP, Brasil.

${ }^{6}$ Grupo de Pesquisa em Educação Ambiental, Faculdade de Ciências, UNESP - Univ Estadual Paulista, campus de Bauru, Programa de Pós-graduação em Educação para a Ciência, Bauru, SP, Brasil.

${ }^{9}$ Centro de Ciências Humanas e da Educação (CCHE), Universidade Estadual do Norte do Paraná (UENP), Departamento de Ciências Biológicas, Jacarezinho, PR, Brasil.

${ }^{10}$ Faculdade de Ciências da Saúde, Departamento de Psicologia, Garça, SP, Brasil.

${ }^{12}$ Centro de Ciências Tecnológicas, Universidade do Estado de Santa Catarina (UDESC), Departamento de Matemática, Joinville, SC, Brasil.
}

${ }^{13}$ Quando escrevemos professor, aluno, entrevistado e educador ambiental estamos referindo-nos aos sujeitos tanto do gênero masculino como do feminino. 
apropriação de conhecimento em EA, considerando que estes materiais são 'síntese de múltiplas determinações', isto é, são elementos reveladores de diversas dimensões do quadro da inserção da EA nas escolas de Educação Básica, apontando: concepções de EA, conteúdos trabalhados, estratégias escolhidas, e até a forma como a EA está inserida no processo de formação dos sujeitos.

\section{Metodologia}

No delineamento do estudo, estabelecemos, como problema de pesquisa, a identificação e análise das diferentes fontes de informação dos professores da Educação Básica sobre EA como subsídio na elaboração de diretrizes gerais para a divulgação de conhecimentos acadêmicos e científicos necessários à prática educativa ambiental crítica, transformadora $\mathrm{e}$ emancipatória.

Com esse problema de pesquisa orientando nossas ações, o estudo intitulado 'Fontes de informação dos professores da Educação Básica: subsídios para a divulgação de conhecimentos acadêmico-científicos sobre EA' (TOZONI-REIS, 2010) cumpriu várias etapas. $\mathrm{Na}$ primeira, realizamos um mapeamento para identificar os professores que trabalham com EA nas escolas dos 14 municípios da região delimitada: identificamos 948 professores. Na segunda etapa, realizamos entrevistas com 277 professores das escolas mapeadas para coleta de dados, seguida de observações nessas escolas. Na terceira etapa, dedicamo-nos à organização dos dados em categorias para análise, e, na ultima etapa, realizamos a análise dos dados e a redação do Relatório Final. É muito importante observar que todas as etapas foram planejadas, realizadas e avaliadas coletivamente pelos membros do Grupo de Pesquisa.

Os resultados de todas essas etapas do estudo, analisados coletivamente, revelaramnos importantes dados da realidade da inserção da EA na escola, que organizamos em cinco categorias: concepção de EA; atividades desenvolvidas; dificuldades encontradas; fontes de informação; e sugestões para fontes de informação.

\section{Apresentação e discussão dos dados}

O dado mais significativo da pesquisa diz respeito à fragilidade da inserção da EA na escola, que, em nosso estudo, apareceu, primeiramente, na dificuldade dos professores entrevistados em compreenderem os próprios objetivos da pesquisa, ainda que esclarecê-los fosse a maior preocupação dos pesquisadores. A maioria dos professores entrevistados seguiu confundindo e sobrepondo a identificação das fontes de informação com as atividades e materiais didáticos utilizados por eles em sala de aula. Essa aparente dificuldade, analisada, mostrounos que um número bastante significativo dos professores declarou realizar suas pesquisas e seu estudo sobre a EA no mesmo material didático oferecido aos alunos, dentre os quais estão: as revistas, jornais e os livros didáticos. Os professores citam como suas fontes de informação: revistas (23\%), internet (14\%), materiais paradidáticos (14\%), livro didático (13\%), jornais $(10 \%)$, apostilas $(6 \%)$, livros em geral (6\%), vídeos, filmes e músicas (4\%), cursos, palestras e panfletos $(3 \%)$, matérias acadêmicas $(3 \%)$ e programas de TV $(3 \%)$, seguidos de 
projetos e práticas educativas (2\%), legislação, normas e diretrizes $(1 \%)$ e artigos em geral (menos de 1\%).

Analisamos esses dados com duas preocupações fundamentais: a primeira referida à função das fontes de informação na prática educativa ambiental desses professores, e a segunda ao tipo de informação que eles buscam. Como podemos notar, a maior parte das fontes utilizadas são, na verdade, materiais didáticos ${ }^{14}$. Entendemos que o material que os professores fornecem aos alunos não deve ter função formativa para os próprios professores, pois, segundo a perspectiva teórica que adotamos - a pedagogia histórico-crítica - os conteúdos de ensino têm função central no processo educativo, esperando-se, desta forma, que os professores tenham sobre eles total domínio. Nossa principal preocupação neste sentido foi identificar os condicionantes históricos dessa prática, refletindo sobre o contexto social, político, econômico e pedagógico do esvaziamento da dimensão intelectual do trabalho dos professores.

As revistas e os jornais foram as fontes de informação de maior peso na formação dos professores como educadores ambientais (33\% do total). Além da revista Nova Escola, a mais citada pelos professores, outras revistas com citações significativas foram: Veja, Superinteressante e Época. As revistas científicas foram insignificantemente citadas, visto que houve uma única citação da revista Ciência Hoje, que traz conteúdos mais próximos às disciplinas de ciências, biologia, química, física e matemática.

Em nossas análises, essas fontes de informação apontadas pelos professores são, na realidade, meios de comunicação para o grande público, não tendo como preocupação a transmissão de conhecimentos e conteúdos mais elaborados do ponto de vista escolar, pois trazem informações genéricas para serem rápida e instantaneamente consumidas pelos leitores. Podemos considerar que esse tipo de material impresso pode servir como material didático nas escolas de educação básica, para ser trabalhado com alunos, pois, pela atualidade dos temas e pela linguagem mais próxima da vida prática dos alunos, são motivadores do processo de ensino e aprendizagem. Porém, não podemos esquecer que atividades com esse tipo de recurso exigem mediação constante dos professores para que possa ser considerada uma atividade de ensino com qualidade, no sentido de apropriação crítica do saber elaborado pela cultura. No entanto, consideramos que esse tipo de publicação é insuficiente e inadequada para o processo de formação dos professores para tratar do tema ambiental nas escolas. Como consequência, identificamos nessa prática educativa ambiental uma situação preocupante no que diz respeito aos conhecimentos que, embora encontrados em fontes muito variadas, são tratados de forma fragmentada e superficial do ponto de vista do necessário domínio dos saberes escolares para a inserção da temática ambiental. Isto revela uma ação educativa muito mais próxima da ideia de consciência ingênua - no caso, sobre a temática ambiental - que discutiu Paulo Freire (1989), e do senso comum educacional discutido por Dermeval Saviani (1991), quando sabemos serem necessárias a consciência crítica e a consciência filosófica por parte

\footnotetext{
${ }^{14}$ Materiais didáticos são concebidos, neste texto, como todo e qualquer material utilizado no contexto de um procedimento de ensino visando o aprimoramento do processo ensino-aprendizagem. Material didático, portanto, é um instrumento ou ferramenta que o professor escolhe, cria, produz, seleciona e utiliza para facilitar o processo de transmissão e assimilação do conteúdo que ele trabalha com os alunos.
} 
dos professores, uma demanda legítima e necessária a qualquer processo educativo em nossa sociedade.

Em nossas análises, destacamos a revista Nova Escola, por ter sido a mais citada pelos professores entrevistados. Buscamos em Bueno (2007), que, fundamentado nos pressupostos de Adorno (1976 apud BUENO, 2007) sobre a indústria cultural e a semiformação, produziu importantes contribuições. Esse autor destaca que esta revista, produção do Grupo Abril, prioriza um vocabulário simplificado e a disseminação de muitas ilustrações que apresentam professores e alunos 'sorridentes'. Ao concebê-la como uma "expressão da semicultura” na sociedade globalizada contemporânea, Bueno (2007, p. 304) destaca:

[...] seu modelo editorial apresenta-se como uma tradução, para termos próprios à educação, do mesmo modelo seguido pelas demais revistas de entretenimento do Grupo Abril. Sua fórmula consistiria, assim, em descaracterizar a categoria "professor" da especificidade que ela possui, reduzindo-a a mais um entre outros estereótipos da indústria cultural. Assim como para a adolescente vende-se Capricho, para a mulher madura vende-se Nova, para o macho vende-se Playboy, para o homem de negócios vende-se Exame, da mesma forma, para o professor, vende-se Nova Escola. [...] Enquadrado como mais um entre os estereótipos da sociedade de massas, o professor, ao lado da adolescente, da mulher madura, do macho, do homem de negócios etc., vê-se anulado como um sujeito universal capaz de pensar o todo. Desincumbido de sua especificidade, ao professor resta apenas o consumo distraído de fórmulas que o põem em sintonia com uma totalidade que assim permanece imune à crítica.

Nesta ótica, podemos dizer que as fontes de informações citadas pelos professores, como as revistas e os jornais, ao divulgarem informações genéricas e superficiais sobre o tema ambiental para uma leitura de massas, não são publicações voltadas para a formação profissional e específica dos professores, se considerarmos essa formação sob a perspectiva da pedagogia histórico-crítica. Essa situação se torna ainda mais inadequada se lembrarmos que os professores, em geral, utilizam-se destas informações e as reproduzem diretamente para os alunos, sem uma reflexão própria, mediada pelos seus conhecimentos específicos para a prática educativa ambiental.

Além das revistas e jornais, outras fontes de informação indicadas pelos professores foram os materiais paradidáticos e a internet (igualmente 14\% cada). Dentre os materiais paradidáticos, foram citados diversos materiais que não se caracterizam como aqueles que se apresentam com fins propriamente didáticos, e também não podem ser considerados materiais ou fontes voltadas para a formação do educador ambiental. Muitos dos materiais citados estão relacionados a jogos, cartazes, panfletos, sites, gibis etc. A partir da forma como esse material foi apontado nas entrevistas, concluímos que não são utilizados para a formação do professor como educador ambiental, mas estão mais próximos de recursos didáticos que os professores usam com seus alunos. 
A análise dos conteúdos das entrevistas nos permite afirmar que a internet foi citada como fonte de informação de maneira muito genérica. Os professores afirmaram realizar pesquisas em sites para obter informações sobre os temas ambientais locais ou globais, e para esclarecimento de alguns temas ambientais encontrados em livros, jornais e revistas. Neste sentido, o site de busca Google foi o mais citado. Nossas análises partiram da ideia de que a participação das TICs (onde insere-se a internet) em todos os âmbitos de nossa sociedade, inclusive na escola, é evidente, mas que

No âmbito da educação ambiental, percebe-se uma intensificação na produção de material pedagógico, audiovisual e/ou impresso, relacionado ao meio ambiente, [...] contudo, ainda em grande parte não refletem os objetivos explicitados no Programa Nacional de Educação Ambiental e muito menos a realidade sócio-ambiental do lugar, região e país, normalmente tendo uma ótica disciplinar, segmentada, e por vezes tendo como referência apenas valores de determinados segmentos sociais, variando em qualidade e consistência. (RODRIGUES; COLESANTI, 2008, p. 53)

Neste sentido, deve-se ter claro o papel da escola e do professor quando da utilização das TICs, analisando os conteúdos por elas veiculados, contribuindo, assim, para a formação e postura críticas dos alunos. Assim, sem dados mais específicos para compreendermos o papel das TICs como fonte de informação dos professores sobre EA, e pela forma genérica como a internet aparece nos dados coletados nas entrevistas, identificamos a presença deste recurso como secundária, apenas auxiliar, na formação dos professores para a inserção da EA na escola.

Outra fonte de informação que os dados coletados nas entrevistas nos trouxeram foi o livro didático (com 13\% de indicações). Mais uma vez, consideramos este material um recurso didático do qual os professores podem lançar mão para realizarem sua prática educativa junto aos alunos, e não exatamente como fontes de informação na sua formação como educadores ambientais. Mesmo assim, seu uso é tão significativo nas escolas de Educação Básica que o livro didático tem sido muito estudado e criticado. Muitos estudos sobre material didático, como os de Borges (2000), Faria (1989), Fiscarelli (2008) e Freitag (1989), para citar apenas alguns deles, têm mostrado que, embora a tendência mais geral seja considerar positivamente o uso desse recurso didático, tal prática não é neutra e exige o empenho e a formação adequada dos professores para a sua seleção, utilização e produção.

O livro didático é tão importante como material didático no Brasil que o Ministério da Educação tem o Programa Nacional do Livro Didático (BRASIL, 2007) responsável pelas diferentes ações para a consolidação de uma política nacional do livro didático ${ }^{15}$.

${ }^{15}$ É importante destacar que quatro empresas (editoras Moderna, FTD, Ática e Saraiva) dominam 75\% do mercado de livros didáticos destinados à rede pública de ensino - em números do MEC. De acordo com a Associação Brasileira de Editores de Livros (Abrelivros), a movimentação financeira, entre os anos de 2007 e 2008, com a venda de livros didáticos foi de R\$ 523 milhões. 
A crítica mais encontrada nos espaços de discussão acadêmica e científica da educação, com relação a este assunto, diz respeito ao caráter de simplificação - e até banalização - dos conteúdos, assim como às propostas didático-metodológicas memorizadoras que contêm. Desta forma, vemos como o uso desse recurso no trabalho educativo com os alunos merece cuidado.

Para as análises relacionadas ao nosso problema de pesquisa, mais do que a compreensão do uso do livro didático pelos alunos, interessa-nos destacar o fato de que os professores o utilizam como um recurso para a sua própria formação. Os conteúdos das entrevistas sugeriram que por meio desse recurso é que os professores se informam sobre os temas ambientais, no momento em que os utilizam com os alunos, isto é, o livro didático é fonte de informação sobre temas ambientais para a formação profissional dos professores que, assim, parecem não perceber a diferença entre sua atividade formativa e sua prática como educador, já que pudemos observar, pelas respostas dos professores, que sua utilização, de forma bastante significativa, realiza-se sem o necessário questionamento da função do livro didático na relação educativa.

Essa situação colocou-nos uma interessante questão para análise que, embora já bastante explorada pelos estudos em educação, é de importância fundamental para a educação ambiental na perspectiva teórica aqui adotada: a função dos professores no processo educativo. Sabemos da importância que a pedagogia histórico crítica atribui à função mediadora dos professores entre o saber elaborado e a apropriação deste saber pelos alunos. Segundo nosso estudo, porém, pudemos constatar que essa mediação fica a cargo dos materiais didáticos, incluindo o livro didático. Isto é, de mediador entre o saber elaborado e o saber escolar, a função dos professores fica reduzida à apresentação mecânica do saber escolar pelo uso do material didático.

Essa simplificação do trabalho educativo já foi discutida, do ponto de vista histórico, por Alves (2004) ao considerar o manual didático o principal instrumento de trabalho dos professores na fase de universalização da escola burguesa, no início do século XIX. Considerando a ideia central preconizada por Comenius (1976 apud ALVES, 2004) na Didática Magna de "ensinar tudo a todos", o autor destaca que, ao reivindicar uma escola para todos, este pensador desenvolveu a tecnologia fundamental que mediaria a relação entre o professor e o aluno: o manual didático. Desta forma, inspirado pela razão instrumental do então emergente modo capitalista de produção, o trabalho didático foi simplificado de tal maneira que qualquer pessoa poderia ensinar:

O professor, que, até então, precisava ter o domínio de uma erudição muito acima da média, viu-se submetido ao mesmo processo de especialização profissional que já atingira o trabalhador das manufaturas. Como decorrência, a simplificação do trabalho didático gerou o barateamento dos serviços prestados pelos professores e, com isso, a queda dos custos de instrução. Começava-se a tornar viável, portanto, a universalização da educação. Os manuais didáticos, enquanto instrumentos de simplificação do trabalho do professor, assumiram papel central nesse processo. (ALVES, 2004, p. 173). 
Percebe-se, assim, que a divisão do trabalho que caracteriza o modo capitalista de produção começou a determinar a atividade no campo da instrução pública desde seu início, descaracterizando uma das especificidades do papel do professor: o domínio dos saberes. Neste novo modo de produção e organização da vida social, o domínio de técnicas e habilidades é mais valorizado e implica, como atividade educativa, a conquista de uma autonomia prática pelos alunos e pelos professores, de tal forma que o domínio do conhecimento e, ampliando, dos saberes, fica em um plano bem inferior. Não obstante, “[...] o professor deixou de ser um sábio na transição da escola artesanal para a escola manufatureira, as obras dos sábios deixaram de ser referência no âmbito do trabalho didático, sendo substituídas por elaborações de novos especialistas, os compendiadores" (ALVES, 2004, p. 182).

Nesta linha de raciocínio, os 'compêndios' fragmentaram os conhecimentos e os textos clássicos, descontextualizando o contexto de sua produção. Esta perspectiva distancia os professores dos conhecimentos específicos e do processo de elaboração dos estudos sobre conceitos, conteúdos e valores trabalhados em sala de aula, resumindo sua função apenas à transmissão mecânica de conhecimentos e informações para os alunos, caracterizando o aviltamento do trabalho educativo na perspectiva formativa.

Por meio desta análise, podemos identificar quanto as fontes de informação das quais os professores entrevistados lançam mão para inserir a EA no trabalho escolar, na perspectiva de sua própria formação, não têm sido adequadas nem suficientes para que reflitam sobre suas próprias práticas, pois não lhes fornecem elementos consistentes para a elaboração do saber específico que essa inserção exige. A análise mais aprofundada do conjunto das categorias que nos trouxeram os dados, além das fontes de informação, levou-nos à conclusão de que, embora a EA na escola tenha sido objeto de legislação e de diferentes políticas públicas educacionais, nos diferentes níveis e sistemas de ensino, ainda não está inserida na educação escolar de forma significativa. Lembremos que as entrevistas foram realizadas com os professores indicados pela coordenação das escolas como sendo aqueles que trabalham com a EA em suas instituições. Mesmo assim, os dados coletados em todas as entrevistas e analisados nas cinco categorias mencionadas têm, como resultado comum, a fragilidade da inserção da EA na educação escolar.

Desta forma, não seria exagero dizer que as fontes de informação utilizadas pelos professores entrevistados em nosso estudo contribuem para vulgarizar e generalizar os conhecimentos teóricos, específicos e práticos necessários à inserção da EA nas escolas. No entanto, é de fundamental importância considerar que esta vulgarização não pode ser atribuída única e diretamente aos professores que atuam na rede pública de ensino, pois reconhecemos que sua prática educativa realiza-se em condições complexas de exploração de trabalho, de perda de autonomia e de banalização do conhecimento, elementos fundamentais para a compreensão da qualidade do ensino, em especial, da qualidade do ensino público. Desta forma, consideramos que os dados que nos trouxeram os professores, para compreendermos as fontes de informação das quais lançam mão para sua formação como educadores ambientais, exigiram um aprofundamento dos estudos sobre a crise de qualidade do ensino público no Brasil, o que não poderia ser empreendido senão em uma perspectiva histórica. 


\section{Análises}

A primeira ideia a considerar sobre a educação escolar no Brasil é a de que esta foi e ainda é - historicamente dual (ROMANELLI, 2009). Desde a origem da educação escolar tivemos um ensino diferenciado para as diferentes camadas sociais, com poderes políticos e econômicos distintos: esta é a tese da dualidade de Romanelli (2009), que se expressa em diferentes momentos históricos, embora com conteúdos um pouco diferentes em cada um deles.

A história da educação no Brasil inicia-se no período Colonial, com o monopólio da Igreja contrarreformista representada pela Companhia de Jesus. Nesse período, a educação caracterizou-se pela implantação de um processo de aculturação dos índios pela catequese, além da formação ideológica dos filhos dos colonos, enquanto já marcava a dualidade do então incipiente sistema de ensino, que oferecia um ensino academicista aos filhos dos senhores de terra que, de modo geral, completavam os seus estudos na Europa. Mesmo com a expulsão dos jesuítas do Brasil pelo Marquês de Pombal, em 1759, e a inserção dos ideários iluministas, essa dualidade não foi superada.

Em 1822, no período Imperial, a elaboração de uma Constituição trouxe ideias leigas para a organização do ensino. Fortemente inspirada nos escritos de Condorcet para a organização do ensino após a Revolução Francesa, a ‘Memória de Martim Francisco’ foi uma proposta de instrução pública fundamentada na concepção laica de escola da burguesia francesa. A diferença entre educação e instrução - públicas - explicitava essa concepção: educação para todos, mas dosada e controlada, como convinha a uma sociedade de classes. Mesmo considerando que tal proposta não tenha se efetivado, sombreada pelo projeto de criação de universidades, a mesma expressava a continuidade da lógica dual de organização do ensino desde o Brasil colônia, o que pode ser ilustrado pelo dado apresentado por Saviani (2007) de que, em 1840, a média de recursos destinados à educação era de 1,8\% do orçamento do governo imperial ( $0,47 \%$ para a instrução primária e secundária).

Com a chegada da República, em 1889, a mão de obra escrava foi substituída pelo trabalho livre; a cafeicultura estava em expansão, o 'liberalismo' da república era controlado pelo Estado - o que significava, pelas elites - e a educação organizava-se ainda pela lógica dual. Os processos de industrialização e de urbanização trouxeram, pela primeira vez no Brasil, em 1920, pela mão de Sampaio Dória, a discussão da educação das massas populares. Também no Brasil, portanto, vemos confirmada a tese de Enguita (1989) de que a escola de massas - a escola para todos, tal como a conhecemos hoje - refere-se à escola moderna, que assumiu, no desenvolvimento urbano industrial, a tarefa de preparar a população para o trabalho na indústria. Tivemos, então, o que Nagle (1974) chamou de "entusiasmo pela educação" - expansão da rede escolar de ensino - e "otimismo pedagógico" - criação de processos mais motivadores para professores e alunos.

Esse movimento cresceu e teve sua maior expressão na publicação do Manifesto dos Pioneiros pela Educação Nova, inspirado na Escola Nova. Temos no Manifesto, do ponto de vista sociopolítico, a educação para todos com caráter liberal: a elite social seria formada não mais pela herança econômica, mas pela oportunidade oferecida pela educação escolarizada. A escola pública defendida no Manifesto, em contraponto à escola da Reforma Francisco Campos, do governo Vargas, era a escola única (significando igualdade de oportunidades), laica 
(livre de doutrinas), gratuita (sob a total responsabilidade do Estado), para ambos os sexos, e obrigatória (até os 18 anos). Para os pioneiros, a função social da escola (campo específico da educação) explicitava-se pela sua organização como instituição social limitada, na sua ação educativa, pela pluralidade e diversidade das forças que concorrem para o movimento das sociedades, considerando que, dentre todos os deveres do Estado, o maior é a educação. Saviani (2007) faz uma cuidadosa análise do Manifesto, considerando-o heterogêneo e contraditório, pois expressa princípios elitistas embora, ao mesmo tempo, igualitaristas. Como documento doutrinário da Escola Nova, traz uma proposta de política educacional em defesa da escola pública e de um sistema nacional de educação pública. No entanto, podemos encontrar nele a marca da dualidade: a escola teria função homogenizadora dos indivíduos nos níveis primários e secundários de ensino, e função diferenciadora no nível superior.

Todos estes embates ocorreram no início dos anos trinta do século XX e, durante o Estado Novo, acirraram-se ainda mais, pois foi regulamentado um sistema de ensino centralista, burocratizado, dualista e corporativista. O pacto com a Igreja manteve uma abordagem de renovação conservadora, isto é, que defendia novos métodos de ensino - Escola Nova - mas, nos aspectos sociopolíticos da educação nacional, era extremamente conservador. Com o fim do Estado Novo, as discussões em torno da Constituição de 1946 trouxeram de volta os Pioneiros, forças hegemônicas na comissão para elaboração da primeira Lei de Diretrizes e Bases da Educação Nacional (LDBN) (BRASIL, 1961). Centrada na figura de Anísio Teixeira, a defesa da escola pública, universal e gratuita foi fortemente atacada pelos católicos, que, identificando-a com a proposta comunista de organização da educação, contrapunham a hierarquia da Família, Igreja e Estado na responsabilidade educacional. Em defesa da escola pública estavam três principais correntes do pensamento pedagógico brasileiro, segundo Saviani (2007): liberal-idealista, liberal-pragmatista e socialista. Por outro lado, esse conflito não ficou restrito aos educadores, empolgando a opinião pública; a imprensa católica e a imprensa leiga fomentaram as discussões para o conjunto da população. A Lei no 4024/61 (BRASIL, 1961) definiu a construção do Plano Nacional de Educação, em 1962. O investimento financeiro na educação subiu para $12 \%$ dos recursos da União, e a política educacional articulada a esse investimento pretendeu enfrentar o grave problema do analfabetismo, da evasão escolar e do afunilamento do sistema de ensino.

A estrutura criada para o sistema de ensino na década de 1960 foi: Ensino Primário, Ensino Médio (ginasial e colegial) e Ensino Superior. Propunha também a valorização da formação de professores e a implantação do tempo integral nas artes industriais. Essas foram as medidas legais que consolidaram o ensino público. Os movimentos sociais populares do início de 1960 trouxeram importantes discussões acerca da organização do ensino e dos processos educativos. A defesa da cultura e da educação populares foi compreendida como forma de garantir o processo de conscientização necessário para a organização igualitária da sociedade brasileira. Naquele momento, as discussões sobre a escola pública deram lugar a propostas de educação popular vinculadas aos grupos sociais populares mobilizados no período. Esses movimentos tiveram também a participação de um novo setor da Igreja Católica, articulado com a Teologia da Libertação. Um dos mais importantes representantes desse movimento de educação popular, no início da década de 1960, foi Paulo Freire, com a pedagogia libertadora, tendo como referência a Escola Nova e a Teologia da Libertação, sobretudo no que diz respeito à ênfase da atividade sobre os conteúdos, quando, na 'Pedagogia do oprimido', o autor 
mostra a valorização da atividade para a conscientização política transformadora. Todos esses movimentos tiveram fim por ocasião do golpe militar de 1964, que marcou uma ruptura política com a continuidade socioeconômica. O reflexo direto de tal fato na educação se expressa pelas reformas implantadas em busca da 'educação que nos convém': a aprovação da Lei 5.540/68 da Reforma Universitária (BRASIL, 1968) e da Lei 5.692/71 (BRASIL, 1971), que organizou o Ensino Básico em primeiro e segundo graus. O pano de fundo das reformas foi a teoria do capital humano com seus princípios da racionalidade, eficiência e produtividade, isto é, o máximo de resultados com o mínimo de esforços investidos na formação humana. Essas reformas, portanto, inspiraram-se na pedagogia tecnicista, articulando a organização racional (taylorista) do sistema de ensino brasileiro com o controle de comportamento nos processos de aprendizagem (behaviorismo).

Talvez a análise histórica que mais interessa ao nosso estudo, no sentido da compreensão da crise de qualidade da escola pública, esteja expressa nos dados coletados junto aos nossos entrevistados e que diz respeito à tendência da vulgarização do conhecimento escolar. Podemos considerar a política educacional do período da ditadura militar (1964-1985) a sua principal definidora. Lembremos que, durante este período, a escola pública expandiu-se de forma significativa, pois o modelo econômico em desenvolvimento exigia a escolarização da população, enquanto o modelo político exigia o controle da mesma. Assim, o governo autoritário equacionou essa aparente contradição pela 'expansão controlada', isto é, expandiu a rede pública de ensino criando o que Romanelli (2009) chamou de mecanismos internos de controle: o controle da progressão no sistema e o controle da qualidade da educação. A dualidade neste período, cujos reflexos vivemos ainda hoje, expressou-se pela oposição quantidadequalidade: enquanto se expandia o atendimento à educação escolarizada pública pelo estado autoritário (quantidade), privatizava-se, gradualmente, a qualidade.

Foi neste clima de expansão controlada do ensino público que chegaram, ao Brasil, as teorias críticas da educação, desenvolvidas em várias partes do mundo. Bourdieu e Passeron, Althusser, Baudelot e Establet e Bowles e Gintes foram as principais referências neste sentido. Essas teorias são conhecidas como teorias críticas reprodutivistas, pois desenvolveram muitos estudos sobre o papel da escola na reprodução das condições sociais vigentes (SAVIANI, 2007). Essas teorias, de caráter denunciatório, estimularam a discussão das teorias críticas transformadoras da educação no Brasil.

Assim, chegamos à década de 1980 no Brasil, com o fim da ditadura militar, um período bastante fecundo para as discussões sobre a educação e a organização do ensino, em especial, a escola pública na perspectiva crítica e transformadora. No entanto, essas posições críticas representavam um setor que, embora tivesse muita penetração entre os educadores, não se consolidou como hegemônico na definição de uma linha político-pedagógica crítica e transformadora na organização do sistema de ensino. Podemos afirmar que a política oficial centrava-se na expansão do ensino, e as forças contra-hegemônicas apontavam duas correntes distintas: a renovação dos processos de ensino propostos pela educação libertadora, sobretudo no que diz respeito ao processo de conscientização dos sujeitos educandos; e, de outro lado, a valorização, na educação escolar, das tendências marxistas em defesa da escola pública. Porém, as forças hegemônicas neoliberais avançavam no campo das políticas públicas da educação.

Essa situação se expressa, de forma muito clara, no processo de elaboração da nova Lei de Diretrizes e Bases da Educação Nacional (LDB), que, iniciado em 1988 com a promul- 
gação da Constituição Federal, consolidou-se na promulgação da Lei no 9.394/96 (BRASIL, 1996). A Constituição Federal, elaborada por um Congresso Constituinte apoiado pela população entusiasmada com o fim da ditadura e o início da redemocratização da sociedade, organizou o sistema de ensino no Capítulo da Educação, expressando algumas vitórias e muitas derrotas nas teses defendidas pela mobilização em defesa da escola pública. O clima de entusiasmo pela redemocratização arrefeceu frente ao avanço da reforma do Estado inspirado na doutrina neoliberal. A nova LDB, instrumento político da organização da educação no Brasil, traz a marca do neoprodutivismo (SAVIANI, 2007), ou seja, a renovação neoliberal da teoria do capital humano. Essa abordagem fez com que a LDB aprovada se tornasse um instrumento para a política educacional marcada pela inclusão-excludente: aos avanços quantitativos (necessários) na inclusão da população em idade escolar na escola pública, não se considerou a qualidade necessária, excluindo, pelo aprofundamento da crise de qualidade na escola pública, enorme parte da população do processo de apropriação da cultura como instrumento transformador da prática social.

Então, se a escola pública no Brasil tem uma trajetória histórica marcada pela tardia implantação de um sistema nacional de ensino, caracterizado, nos diferentes momentos históricos, como excludente e dual, que lições essa história nos traz? Frigotto (2005), analisando a escola pública atual nessa perspectiva histórica, identifica, nessa trajetória, três projetos de desenvolvimento da sociedade brasileira, em disputa no século XX, que esclarecem o papel da escola pública no Brasil, hoje: o projeto "liberal" (ou neoliberal), o projeto do "desenvolvimentismo conservador", e o projeto do "desenvolvimento econômico nacional e popular" (FRIGOTTO, 2005, p. 225-226). O projeto liberal, como vimos, atravessou praticamente todo o século XX como hegemônico, com poucos períodos de interrupção, derrubando e assimilando teses do projeto mais conservador. O projeto do desenvolvimento popular cresceu no final da ditadura militar, e consolidou-se no início da década de 1980. Terminamos o século XX, portanto, com a escola pública estruturada por reformas educacionais fundamentadas na teoria do capital humano, ou seja, por reformas que trouxeram a marca do economicismo na educação: a submissão do projeto educacional aos interesses econômicos das elites no Brasil.

A redemocratização da sociedade brasileira desembocou no neoliberalismo, tentado pelo Governo Collor, consolidado pelo Governo Fernando Henrique Cardoso e aprofundado pelos Governos Lula e Dilma. Nesse sentido, as políticas públicas foram todas ajustadas de modo a garantir a desregulamentação de direitos, a descentralização de responsabilidades e a investida na privatização do que é público.

A alternativa ao projeto neoliberal consolidado durante a década de 1990, um projeto de desenvolvimento econômico nacional e popular, chegou ao poder pela eleição do Presidente Lula, em 2002, mas agiu de forma a aprofundar ainda mais o ajuste neoliberal da economia globalizada, consolidando uma perspectiva flexibilizadora da responsabilidade do Estado em relação às políticas públicas, mesmo se considerarmos as contradições - cada vez menores nos espaços de gestão das políticas públicas deste governo.

Se, no início da organização do sistema nacional de ensino no Brasil, a disputa era entre a escola pública e a escola privada, no que diz respeito à responsabilidade da Igreja e do Estado, a análise do funcionamento do sistema de ensino hoje está centrada na qualidade da escola pública e da escola privada. Mas, qual qualidade? De direito social de todos, a educação é compreendida pela ideologia dominante - impregnada pela doutrina econômica neoliberal e 
construída pela lógica do neoprodutivismo na educação - como um serviço a ser prestado e adquirido no mercado (FRIGOTTO, 2005; SAVIANI, 2007). Uma pequena parcela da população - poderosa do ponto de vista econômico e político - tem, na escola privada, uma melhor qualidade de ensino, enquanto, para a grande maioria da população, a escola pública oferece menor qualidade, pelo menos no que diz respeito à apropriação de conhecimentos. No entanto, é preciso considerar que a qualidade do ensino não se explica por si só. Demo (2007) argumenta que a tese da qualidade da escola privada é um "imbróglio educacional", pois, se considerarmos que a escola privada no Brasil organiza-se a partir da lógica neoprodutivista para - e somente para - o sucesso dos alunos no próprio sistema de ensino (tendo o Ensino Superior como meta), reconheceremos que, do ponto de vista da formação plena dos sujeitos sociais para a construção de uma sociedade mais equilibrada, a escola privada também carece de qualidade. No entanto, se a Educação Básica - e o ensino - como direito social é mercadoria a ser adquirida no mercado, a qualidade de ensino na lógica neoprodutivista é um valor agregado à mercadoria escola privada, tornando-a mais atrativa para os grupos dominantes, que podem comprá-la. A qualidade da educação, portanto, de formação humana plena, passa a ser qualidade diretamente relacionada aos interesses imediatos e aos valores éticos e políticos das elites dirigentes: individualismo, competição, consumismo etc.

No que diz respeito à escola pública, os professores, de mediadores no processo de apropriação de conhecimentos sistematizados da cultura elaborada, com vistas à formação plena dos sujeitos sociais, assumem, na lógica hegemônica da organização da sociedade, o papel de prestadores de serviço. Nesse sentido, sua formação para dirigir sofisticados processos de ensino e aprendizagem - processos que exigem conhecimentos específicos - que garantam a apropriação crítica e reflexiva da cultura elaborada na perspectiva de formação crítica, transforma-se numa formação superficial.

Chauí (2003) faz importante análise do sentido neoliberal e neoprodutivista da proclamada educação continuada desses professores. A política de contratação de professores substitutos, a existência ainda significativa de professores leigos - e, em nova versão, os professores eventuais - e a valorização de educadores voluntários na escola são reflexos dessas referências na organização da escola pública. Essa pseudoparticipação dos grupos sociais privilegiados, na forma do voluntariado em busca de qualidade na escola pública, pode ser compreendida, por exemplo, quando identificamos os protagonistas dos hoje tão conhecidos programas, como, por exemplo, o dos amigos da escola. Identificados os protagonistas, identificamos sua inserção de classes e os interesses econômicos, políticos e sociais que os movem.

Outra dimensão importante da flexibilização da educação como direito de todos, que está na base da simplificação do trabalho docente, foi identificada por Frigotto (2005, p. 233): a "privatização do pensamento pedagógico". Saviani (2007) analisou essa privatização do pensamento pedagógico identificando quatro categorias. A primeira categoria, o neoprodutivismo, fundamentado na teoria do capital humano re-significado, busca organizar o ensino a partir da necessidade de formação humana para as novas formas de produção, flexibilizadas. Isso significa que a formação escolar pretendida refere-se às capacidades e competências, presentes e expressas nos documentos que traçam parâmetros e diretrizes curriculares para a Educação Básica. Assim, os princípios da Escola Nova, também ressignificados, constituemse na segunda categoria, que ele definiu como neo-escolanovismo, isto é, o aprender a aprender que agora também é formação continuada dos sujeitos educandos. Como terceira catego- 
ria, encontramos o neoconstrutivismo, expresso, particularmente, pela teoria do professor reflexivo: os saberes docentes centrados na prática, na experiência cotidiana. A reflexão aqui, cujos fundamentos estão na pedagogia das competências, nos comportamentos flexíveis e na responsabilidade individual, diz respeito à compreensão pragmática da experiência docente, ressignificando também o tecnicismo, quarta categoria. Se, na década de 1970, os princípios são de racionalidade, eficiência e produtividade sob o controle direto do Estado, agora, aparecem sob o controle do mercado, a responsabilidade da iniciativa privada e das organizações não governamentais, reduzindo os investimentos públicos pelas parceiras público-privadas.

Essas são algumas das reflexões históricas, pedagógicas e políticas realizadas para compreendermos como a crise de qualidade da escola pública e o agravamento da simplificação do papel dos professores dão novos sentidos aos depoimentos de nossos entrevistados, no que diz respeito às fontes de informação para sua formação. Nossos dados, quando analisados na perspectiva aqui apresentada, nos mostram que os professores tratam de forma simplista e superficial a EA na escola, mas são também - e ao mesmo tempo - vítimas desse processo de simplificação da ação docente, que tem dimensões históricas e políticas.

\section{Conclusões}

A função dos professores, na atual concepção em que se encontra o sistema de ensino no Brasil, é de desenvolver competências e habilidades nos alunos com a finalidade de prepará-los para atingirem metas estabelecidas pelas matrizes de referências instituídas pelos sistemas de avaliação. Isto é, ao invés dos sistemas de avaliação estabelecerem critérios de qualidade para diagnosticar o processo de apropriação dos saberes escolares, são esses sistemas que criam critérios de organização do ensino. Desta forma, a função dos professores afasta-se da função de mediador no processo de apropriação dos saberes para a formação humana plena, para assumir a 'aplicação' de atividades que garantam um bom desempenho dos estudantes nas avaliações de suas competências e habilidades.

É neste contexto que as políticas públicas excluem os professores do processo formativo mais complexo, privando-os de sua autonomia. Assim, os manuais, livros didáticos, apostilas e demais fontes de informação, identificadas neste estudo como fontes utilizadas pelos professores para a inserção da EA na escola, tornam-se inapropriadas e insuficientes, pois não favorecem que os professores reflitam - num sentido mais aprofundado - sobre sua prática em uma dimensão mais ampla e estrutural.

Sabemos que esses sistemas de avaliação têm sido muito utilizados em diversos países da América do Sul e, portanto, também merecem uma análise abrangente e histórica sobre a forma que se expressam e determinam a prática educativa dos professores. Alves (2003), ao assumir os pressupostos da matriz teórica referida por Marx em 'A Ideologia Alemã', como ciência da História, nos lembra que "o singular é a manifestação, no espaço convencionado, de como as leis gerais do universal operam dando-lhe uma configuração específica. O universal e o singular, nessa perspectiva, são indissociáveis" (ALVES, 2003, p. 28).

No intento de realizarmos uma reflexão sob esta ótica, e entendendo que a realidade é síntese de múltiplas determinações, nossas análises indicam que as políticas públicas brasileiras são reflexos das exigências prescritas pelos documentos internacionais, que determinam 
o alcance de bons índices educacionais para que os países hegemônicos voltem seus investimentos, por meio de empresas e programas internacionais, aos países periféricos e em desenvolvimento, inculcando uma ideologia neoliberal e a lógica neoprodutivista no sistema educativo brasileiro. Moura (2008), ao refletir sobre a aproximação entre as reformas educacionais brasileiras e a Nova Proposta Curricular do Estado de São Paulo, afirma que:

[...] a relação existente entre as reformas educacionais ocorridas na década de 90 do Século passado que atendem aos interesses de organismos internacionais como o Banco Mundial, a CEPAL, - Comissão Econômica para a América Latina e o Caribe - FMI, - Fundo Monetário Internacional - OREALC, - Oficina Regional de Educação para a América Latina e o Caribe - e UNESCO - Organização das Nações Unidas para a Educação, Ciência e a Cultura, à intervenção do capital para a legitimação da ideologia neoliberal dentro da unidade escolar por meio de pacotes pedagógicos que por fim, alteram drasticamente a atuação do professor, que sem autonomia para desenvolver seu trabalho passa a reproduzir conteúdos pré-determinados. (MOURA, 2008, p. 8-9)

Neste sentido, pode-se afirmar que as competências e habilidades que foram predeterminadas e consolidadas nas orientações estruturadas na Nova Proposta Curricular do Estado de São Paulo (SÃO PAULO, 2008), implantada no ano de 2008, manifestam a ideologia neoliberal e a lógica neoprodutivista. Além das orientações que foram determinadas, observase a designação dos conteúdos nos materiais (apostilas no formato de cartilha) que são enviados às escolas da rede (Equipe Gestora - Diretor, Vice-Diretor e Coordenador Pedagógico; professores e alunos), com especificações detalhadas sobre a forma como devem ser utilizadas por todos os que estão envolvidos no processo educativo (SÃO PAULO, 2008). Embora o discurso dê ênfase à qualidade do ensino, a qualidade não passa de uma retórica vazia, na medida em que simplifica e vulgariza o trabalho educativo dos professores, resumindo-o à reprodução de conteúdos do manual didático, como se esse fosse o principal instrumento pedagógico na relação educativa entre o professor e o aluno.

Esta diluição dos saberes também é, em grande parte, incorporada pelos cursos de formação superior - inicial e permanente - ocasionando a formação precária de profissionais de diversas áreas de estudo e, consequentemente, rebaixando o nível de ensino das universidades, sobretudo em algumas instituições particulares que, em função de sua natureza, colocam a formação de seus alunos em segundo plano, pois seus objetivos são mercantis. Na apresentação à edição brasileira do livro de José Contreras, 'Autonomia de professores', Selma Garrido Pimenta (2002) alerta para o fato desta mercantilização da profissão docente:

[...] no que se refere ao tema das novas configurações do trabalho, o não emprego é uma das características da sociedade globalizada das informações. Nesta, o trabalho autônomo descarta as conquistas trabalhistas, que são dispendiosas para os empregadores, incluindo o estado. Para conseguir trabalho e sobreviver, o trabalhador desempregado necessita buscar, por sua conta, requalificações. E aí se pode com- 
preender a imensa valorização hoje conferida aos programas de formação contínua, transformando a educação em um grande mercado. (PIMENTA, 2002, p. 18)

Assim como as políticas públicas que 'jogam' na escola novas propostas com velhos objetivos, os cursos de formação de professores, nesta perspectiva, caminham para a desprofissionalização destes. Ao invés de se priorizar uma formação que dê centralidade às metodologias e às teorias necessárias para a apropriação de conhecimentos, que fundamentem a prática do professor, o que supõe uma sólida formação, percebe-se, nestes cursos e nas políticas públicas, a redução dos saberes necessários ao exercício da docência em competências técnicas.

Percebe-se, pois, que a formação de professores reproduz um modelo pautado na racionalidade técnica, reproduzindo o modelo neoliberal por meio do desenvolvimento de competências técnicas para a execução de metas e objetivos preestabelecidos. A partir desta abordagem técnica, os professores cumprem metas, atingem objetivos, alcançam índices preeestabelecidos e, entre outros atributos, se transformam em executores de tarefas. Neste contexto, fica evidente a desvinculação: entre a prática e a teoria, entre a prática docente e a pesquisa, entre a prática docente e o estudo, ou, ainda, entre a prática docente e a formação docente. Esse processo, conhecido também como um processo de proletarização do trabalho docente, contribui para a alienação do professor, que fica preso a um cotidiano escolar em que não é estimulado a pensar, em que não lhe é permitido pensar. Assim, podemos dizer que os dados coletados neste estudo reforçam os reflexos da desprofissionalização do trabalho docente: a desvinculação entre prática e teoria parece ser o fundamento da diluição dos saberes por meio do refinamento dos mecanismos de controle das atividades dos professores, expropriando-os de sua condição de sujeitos na apropriação do conjunto de conhecimentos necessários à ação educativa.

É neste mesmo sentido que o formato dos cursos de formação de professores tem se definido, estabelecendo, como tônica, a (de)formação dos professores, que, cumprindo tarefas preestabelecidas em competências, expropriam-se do conhecimento, controlando-os por meio do controle de suas atividades, eminentemente práticas. Observa-se, desta forma, uma estreita relação entre as políticas de formação de professores e as políticas públicas para o ensino: ambas diluem o conhecimento por meio da disseminação de avaliações institucionais, que avaliam competências em detrimento do conhecimento. Em uma perspectiva de superação deste cenário, a formação de professores tem de proporcionar condições para que estes reflitam sobre a complexidade e a especificidade de sua ação profissional, e não aceitem a lógica que está estabelecida e que os considera como meros executores de tarefas.

A formação dos professores para a inserção da EA na escola exige, para superar a situação confirmada em nosso estudo, problematizar os processos formativos, articulando radicalmente a teoria e a prática educativa ambiental. As reflexões empreendidas no decorrer deste estudo indicam a importância da superação do reducionismo com que muitas das ações educativas ambientais tratam a relação teoria e prática, supervalorizando a prática em detrimento da teoria ou considerando-a como prática educativa imediata. Também é importante enfrentar o reducionismo oposto: a supervalorização da teoria em detrimento da prática. Para a superação dos reducionismos com que nos deparamos na ação educativa e, ao mesmo tempo, na ação investigativa de produção e publicação de conhecimentos - sobretudo no mundo 
acadêmico - tomemos como principal referência a práxis. Compreendida em sua forma plena, a práxis permite avançar nessa superação, contribuindo para a investigação, a publicação e a ação educativa ambiental, ao reconduzir, como fundamental, o pensamento e a ação na construção, intencional e consciente, da inserção da EA na educação escolar. A práxis contribui, também, naquilo que lhe é ainda mais específico: a prática, pensada e refletida, sobre a realidade - social e natural - com objetivos transformadores.

A EA se constitui tão complexa e dinâmica que exige, ela própria, um processo educativo fundamentado na reflexão-ação para revelar-se plena de significados concretos da realidade social e ambiental, desvendados naquilo que pode ter de falsos significados. Nesse sentido, uma das possibilidades de reflexão-ação para a EA crítica e transformadora na educação escolar é a formação plena, consciente e consequente dos professores da Educação Básica. Formação essa que, no dia a dia da prática educativa na escola, possa contar com a contribuição das publicações acadêmicas e científicas em EA, desde que estas superem a distância, que pudemos observar, entre o mundo acadêmico e a Educação Básica.

\section{Homenagem}

Dedicamos esse texto à memória de nossa querida Luciana pelo companheirismo, competência, comprometimento e sensibilidade na busca de processos educativos que contribuam para a transformação da realidade em que vivemos para uma sociedade mais justa e bela.

\section{Referências}

ALVES, G. L. A produção da escola pública contemporânea. Campinas: Autores Associados; Campo Grande: Ed. UFMS, 2004.

. Universal e singular: em discussão a abordagem científica do regional. In: ALVES,

G. L. Mato Grosso do Sul: o universal e o singular. Campo Grande: Editora UNIDERP, 2003. p.17-29.

BORGES, G. L. A. Formação de professores de biologia, material didático e conhecimento escolar. 2000. 436 f. Tese (Doutorado em Educação) - Faculdade de Educação, Universidade Estadual de Campinas, Campinas, 2000.

BRASIL. Lei $\mathbf{n}^{\circ} \mathbf{5 . 5 4 0}$, de 28 de Novembro de 1968. Fixa normas de organização e funcionamento do ensino superior e sua articulação com a escola média e dá outras providências. Brasília: Presidência da República, 1968. Disponível em:

<http://www.planalto.gov.br/ccivil_03/Leis/L5540.htm>. Acesso em: 26 abr. 2010.

Lei $\mathbf{n}^{\circ}$ 5.692, de 11 de agosto de 1971. Fixa diretrizes e bases para o ensino de $1^{\circ}$ e $2^{\circ}$ graus, e dá outras providências. Brasília: Presidência da República, 1971. Disponível em: <http://www.planalto.gov.br/ccivil_03/Leis/L5692.htm>. Acesso em: 26 abr. 2010. 
Tozoni-Reis, M. F. C. et al.

Lei $\mathrm{n}^{\circ}$ 9.394, de 20 de dezembro de 1996. Estabelece as diretrizes e bases da educação nacional. Brasília: Presidência da República, 1996. Disponível em: <http://www.planalto.gov.br/ccivil_03/Leis/L9394.htm>. Acesso em: 26 abr. 2006.

Lei $\mathbf{n}^{\circ}$ 4.024, de 20 de dezembro de 1961. Fixa as Diretrizes e Bases da Educação Nacional. Brasília: Presidência da República, 1961. Disponível em: <http://www.planalto.gov.br/ccivil_03/Leis/L4024.htm>. Acesso em: 26 abr. 2011.

. Ministério da Educação. Guia de livros didáticos PNLD 2008: história. Brasília: Ministério da Educação, 2007.

BUENO, S. F. Semicultura e educação: uma análise crítica da revista Nova Escola. Revista Brasileira de Educação, Rio de Janeiro, v. 12, n. 35, p. 300-307, 2007.

CHAUÍ, M. A universidade pública sob nova perspectiva. Revista Brasileira de Educação, Rio de Janeiro, n. 24, p. 5-15, 2003.

DEMO, P. Escola pública e escola particular: semelhanças de dois imbróglios educacionais. Ensaio: avaliação e políticas públicas em educação, Rio de Janeiro, v.15, n. 55, p.181-206, 2007.

ENGUITA, M. A face oculta da escola. Porto Alegre: Artes Médicas, 1989.

FARIA, A. L. G. Ideologia do livro didático. São Paulo: Cortez, 1989.

FISCARELLI, R. B. O. Material didático: discursos e saberes. Araraquara: Junqueira \& Marins Editores, 2008.

FREIRE, P. Pedagogia do oprimido. 13. ed. Rio de Janeiro: Paz e Terra, 1989.

FREITAG, B. O livro didático em questão. Campinas: Autores Associados, 1989.

FRIGOTTO, G. Escola pública brasileira na atualidade: lições da história. In: LOMBARDI, J. C.; SAVIANI, D.; NASCIMENTO, M. I. M. (Org.). A escola pública no Brasil: história e historiografia. Campinas: Autores Associados, 2005. p. 221-259.

MOURA, M. R. L. Reformas educacionais e a proposta curricular do Estado de São Paulo: primeiras aproximações. In: SEMINÁRIO DO TRABALHO, 6., 2008, Marília. Anais eletrônicos... Marília: UNESP, 2008. Disponível em: < http://www.estudosdotrabalho.org/ anais6seminariodotrabalho/marcilenemoura.pdf $>$. Acesso em: 25 mar. 2010.

NAGLE, J. Educação e sociedade na primeira república. São Paulo: E.P.U.: Edusp, 1974.

PIMENTA, S. G. Apresentação à edição brasileira. In: CONTRERAS, J. Autonomia de professores. São Paulo: Cortez, 2002. p. 11-21.

RODRIGUES, G. S. S. C.; COLESANTI, M. T de M. Educação ambiental e as novas tecnologias de informação e comunicação. Sociedade $\boldsymbol{\&}$ Natureza, Uberlândia, v. 20, n. 1, p. 51-66, 2008. Disponível em: <http://www.seer.ufu.br/index.php/sociedadenatureza/ article/viewFile/9398/5743>. Acesso em: 13 jan. 2011. 
A inserção da Educação Ambiental na Educação Básica: ...

ROMANELLI, O. O. História da educação no Brasil. 34. ed. Petrópolis: Vozes, 2009.

SÃO PAULO (Estado). Secretaria de Estado da Educação. Edição especial da proposta curricular. Revista do Professor, São Paulo, 2008. (Edição especial).

SAVIANI, D. Do senso comum à consciência filosófica. São Paulo: Autores Associados, 1991.

2007.

História das idéias pedagógicas no Brasil. Campinas: Autores Associados,

TOZONI-REIS, M. F de C. Fontes de informação dos professores da educação básica: subsídios para divulgação dos conhecimentos acadêmicos e científicos sobre educação ambiental. Botucatu: [s.n.], 2010. (Relatório Final - Processo FAPESP no 2007/ 56374-5).

TRAJBER, R.; MENDONÇA, P. R. (Org.). O que fazem as escolas que dizem que fazem educação ambiental? Brasília: Ministério da Educação: Unesco, 2006.

VEIGA, A.; AMORIM, E.; BLANCO, M. Um retrato da presença da educação ambiental no ensino fundamental brasileiro: o percurso de um processo acelerado de expansão. Brasília: INEP, 2006 (Série Documental).

Artigo recebido em 02/05/12. Aceito em 30/10/12. 